\title{
Relationship between the growth regime of polyelectrolyte multilayers and the polyanion/polycation complexation enthalpy.
}

Nicolas Laugel, Cosette Betscha, Mathias Winterhalter, Jean-Claude Voegel, Pierre Schaaf and Vincent Ball.

\section{Supporting Information :}

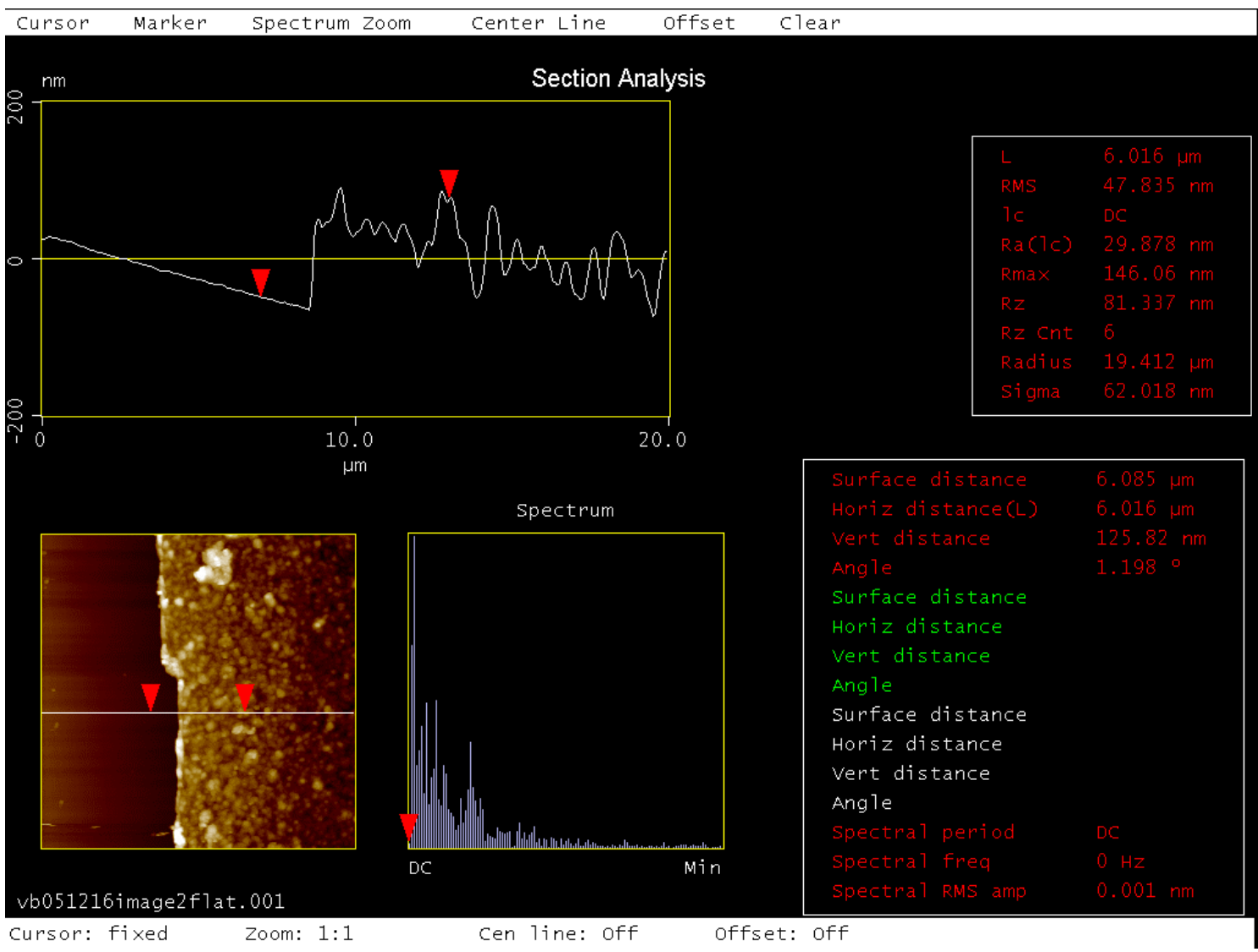

Figure 1 : AFM section obtained in the contact mode and in air of a PEI-(PGA-PAH) 24 bilayer build up on a silica slide in the presence of $1 \mathrm{mM}$. $\mathrm{NaCl}$ (the $p H$ was adjusted to 7.4). 